\title{
PRÁTICAS DE RESPONSABILIDADE SOCIAL CORPORATIVA E GESTÃO DE PESSOAS NO CONTEXTO BRASILEIRO: UMA ANÁLISE DAS EMPRESAS MODELO EM SUSTENTABILIDADE E MELHORES PARA TRABALHAR
}

\author{
CORPORATE SOCIAL RESPONSIBILITIES PRACTICES IN \\ BRAZILIAN CONTEXT: AN ANALYSIS OF BUSINESS MODEL FOR \\ SUSTAINABILITY AND BEST PLACE TO WORK
}

Data de submissão: 04/09/2013 Aceite: 05/04/2014

\author{
Simone Alves Pacheco de Campos ${ }^{1}$ \\ Taís de Andrade ${ }^{2}$ \\ Vania de Fátima Barros Estivalete ${ }^{3}$ \\ Vivian Flores Costa 4 \\ Aline Armanini Stefanan ${ }^{5}$
}

\section{RESUMO}

Este trabalho tem como objetivo analisar as práticas de Responsabilidade Social Corporativa (RSC) e as práticas de Gestão de Pessoas nas organizações consideradas modelo em sustentabilidade, RSC e melhores empresas para trabalhar. Realizou-se uma pesquisa através dos Guias Exame de Sustentabilidade e Melhores Empresas para Trabalhar, da Editora Abril S.A, compreendendo o período de 2006 a 2011. Ao analisar as práticas de RSC associadas à dimensão Social/Cultural, observou-se que os resultados expõem uma maior preocupação com o apoio à educação e com o desenvolvimento local. Em relação à dimensão ambiental/ecológica da RSC, constatou-se o predomínio de práticas relacionadas ao uso de materiais recicláveis. As práticas de Gestão de Pessoas priorizadas sinalizam ações tradicionais, resultando em menor preocupação com os aspectos sociais, comportamentais e éticos. As organizações investigadas são consideradas modelo em GP e RSC, porém foram evidenciadas lacunas relacionadas à interação da Gestão de Pessoas com as práticas de RSC, a dentro das empresas.

Palavras-chave: Responsabilidade Social Corporativa; Gestão de Pessoas; práticas organizacionais.

\footnotetext{
${ }^{1}$ Possui graduação em Administração pela Universidade Federal de Santa Maria - UFSM, mestrado em Programa de Pós-Graduação em Administração pela Universidade Federal de Santa Maria - UFSM e doutorado em Administração pela Universidade Federal do Rio Grande do Sul - UFRGS. Porto Alegre. Rio Grande do Sul. Brasil. E-mail: simoneapcampos@gmail.com

${ }_{2}^{2}$ Possui graduação em Administração pela Universidade de Passo Fundo - UPF, graduação em Administração de Empresas pelo Centro Universitário Franciscano - UNIFRA, mestrado em Administração pela Universidade Federal de Santa Maria - UFSM e doutorado em andamento em Administração pela Universidade Federal de Santa Maria - UFSM. Atualmente é professora na Unidade Descentralizada de Educação Superior da UFSM em Silveira Martins - UDESSM. Silveira Martins. Rio Grande do Sul. Brasil. E-mail: tais0206@gmail.com ${ }^{3}$ Possui graduação em Administração pela Universidade Federal de Santa Maria - UFSM, mestrado em Engenharia de Produção pela Universidade Federal de Santa Maria - UFSM e doutorado em Agronegócios pela Universidade Federal do Rio Grande do Sul - UFRGS. Atualmente é professora da Universidade Federal de Santa Maria - UFSM. Santa Maria. Rio Grande do Sul. Brasil. E-mail: vaniaestivalete@ufsm.br

${ }^{4}$ Possui graduação em Administração pela Universidade Federal de Santa Maria - UFSM, graduação em Formação de Professores Educação Profissional pela Universidade Federal de Santa Maria - UFSM, mestrado em Administração pela Universidade Federal de Santa Maria - UFSM e doutorado em andamento Administração pela Universidade Federal de Santa Maria - UFSM. Atualmente é professora substituta do Departamento de Ciências Administrativas da UFSM. Santa Maria. Rio Grande do Sul. Brasil. E-mail: vivianfc13@gmail.com ${ }^{5}$ Possui graduação em Administração pela Universidade Federal de Santa Maria - UFSM, graduação em andamento em Estatística pela Universidade Federal de Santa Maria - UFSM e mestrado em andamento em Administração pela Universidade Federal de Santa Maria UFSM. Santa Maria. Rio Grande do Sul. Brasil. E-mail: aline_1934@yahoo.com.br
} 


\begin{abstract}
This study aims to analyses the corporate social responsibility (CSR) and human resource management practices of organizations considered model in sustainability and are best places to work. Thus, we carried out a research by analyzing the Guides Exame de Sustentabilidade e Melhores Empresas para Trabalhar, comprising the period from 2006 to 2011. In relation to practices associated to social/cultural dimension of CSR, the results shows the concern with supporting education and local development. In relation to practices related to environmental/ecological dimension of CSR, there was a predominance of practices related to the use of recyclable materials. The human resource management practices prioritized traditional actions, with less concern with social, behavioral and ethical aspects. Even organizations investigated are model in HRM and CRS, were shown gaps related to the interaction of HRM practices with CSR internally.
\end{abstract}

Keywords: Corporate social responsibility, Human resource management, organizational practices.

\title{
1 INTRODUÇÃO
}

Ao longo das últimas décadas a Responsabilidade Social Corporativa (RSC) está sendo tratada dentro de um movimento acadêmico e prático, que visa integrar os pressupostos da sustentabilidade aos princípios e práticas organizacionais, consubstanciada na ideia de que as organizações devem ter responsabilidades para com a sociedade, abrangendo aspectos sociais, econômicos e ambientais (ELKINGTON, 2004). A noção de Responsabilidade Social Corporativa inclui uma variedade de comportamentos organizacionais, desde os reativos e normativos, até posturas proativas, que a incorporam ao processo decisório organizacional.

As organizações têm buscado integrar responsabilidades sociais, econômicas e ambientais (Elkington, 1994) à estratégia de negócio, tanto para responder às pressões dos seus stakeholders, quanto para adequar-se às normas institucionais. Dentre tais pressões, destacam-se questões relacionadas ao público interno das organizações. Inyang, Awa e Enuoh (2011) afirmam que embora haja um considerável número de estudos sobre o tema, o papel da Gestão de Pessoas na área de RSC, ainda é uma área relativamente nova e inexplorada. Nesse sentido, FuentesGarcia et al. (2007) destacam o papel da Gestão de Pessoas na implementação de práticas de RSC com o público interno, ressaltando que estas perpassam os requisitos mínimos de respeito aos direitos dos trabalhadores, incluindo a implementação de políticas que garantam o equilíbrio e a qualidade de vida no trabalho e aprendizagem contínua.

Jabbour e Santos (2008) advogam que, a atuação da área de Gestão de Pessoas exerce um papel estratégico para que as organizações alcancem resultados sustentáveis através das pessoas, contribuindo para o desenvolvimento social dos indivíduos. Nesse sentido, a área de Gestão de Pessoas torna-se fundamental no desenvolvimento de conceitos e práticas de sustentabilidade e Responsabilidade Social Corporativa, podendo contribuir com ganhos de competitividade organizacional (PFEFFER, 2010). Dessa forma, a Gestão de Pessoas enfrenta o desafio de cumprir os objetivos associados à sustentabilidade econômica, ambiental e social, desenvolvendo ações de forma sistêmica e de longo prazo, voltadas ao desenvolvimento do público interno e a sua integração às estratégias organizacionais (BOUDREAU e TAMSTAD, 2005).

Considerando a relevância do tema Responsabilidade Social Corporativa associado às práticas de Gestão de Pessoas, o presente estudo tem como objetivos: (i) verificar se as empresas modelo em sustentabilidade e RSC, no Brasil, (Guia Exame de Sustentabilidade), no período de 2006 a 2011, apresentam-se também como melhores empresas para trabalhar (Guia Exame Melhores Empresas para Trabalhar) e; (ii) analisar as práticas de Responsabilidade Social Cor- 
porativa e as práticas de Gestão de Pessoas, no âmbito das empresas consideradas modelo em sustentabilidade, RSC e melhores empresas para trabalhar.

Na próxima seção, serão abordados os pressupostos teóricos relacionados à Responsabilidade Social Corporativa, que embasaram o estudo. Na seção seguinte, tratam-se os aspectos metodológicos relacionados à coleta e análise dos dados, para posteriormente (seção quatro) apresentar a análise e a discussão dos resultados. Por fim, na seção cinco, são apresentadas as considerações finais acerca do estudo realizado, limitações e sugestões para pesquisas futuras.

\section{RESPONSABILIDADE SOCIAL CORPORATIVA}

As discussões que enfatizam a importância do comportamento socialmente responsável das organizações não são recentes, uma vez que os primeiros debates acadêmicos datam da década de 1950. Contudo, nota-se que o conceito sofreu mudanças ao longo do tempo, ampliando-se para comportamentos que transcendem as normas e regras legais, contribuindo para a implantação de uma lógica que perpassa todos os negócios da organização.

A defesa de uma abordagem mais tradicional, que tem como o marco inicial o trabalho de Milton Friedman (1970), formou uma longa trajetória de estudos, que foram desenvolvidos em torno das responsabilidades sociais da empresa. No final de 1970, Carroll (1979) ofereceu uma das primeiras concepções, e talvez a mais amplamente aceita, até hoje, dentro do campo de RSC (Matten e Crane, 2005). Segundo o modelo de Carroll (1979), diferentes grupos de stakeholders apresentam demandas distintas para a organização. Contudo, todos os grupos são importantes para a sobrevivência organizacional, daí a necessidade de serem contemplados por uma lógica de responsabilidade social corporativa. Assim, o autor sistematiza as demandas destes diferentes públicos em quatro dimensões: econômica, legal, ética e filantrópica. Acerca do conceito de stakeholders, Teixeira e Moraes (2013) afirmam que, na teoria e na prática organizacional o termo sinaliza as limitações para a legitimação por parte dos seus grupos de interesse, bem como o deságio em identificar quais são e traçar um diálogo para com os mesmos; tendo em vista que ao longo da trajetória, os grupos de interesses nas atividades de toda e qualquer organização se modificam.

Atualmente, uma variedade de conceitos pode ser relacionada ao tema RSC, emergem da diversidade de abordagens teóricas, que incluem ética nos negócios, cidadania corporativa, sustentabilidade corporativa, negócios e sociedade, governança corporativa, dentre outros (Garriga e Melé, 2004; Sasse e Trahan, 2007; Carroll e Shabana, 2010), demonstra ser esse um tema ainda em amadurecimento. Contudo, é possível observar certo consenso em relação ao fato de que, de um modo geral, a responsabilidade social corporativa refere-se a fazer negócios de forma ética e sustentável, levando em consideração os interesses dos stakeholders (Panapanaan et al., 2003). Em consonância com o exposto, McWilliams, Siegel e Wright (2006) definem a RSC como situações em que a empresa vai além da conformidade exigida por lei, resultando em ações que promovem algum bem social, para além dos interesses da empresa.

A partir destas concepções, percebe-se que a maioria das pesquisas sobre a temática encontra-se alicerçada na Teoria dos Stakeholders (FREEMAN, 1984, CLARKSON, 1995). Segundo esta abordagem, a gestão organizacional recebe influência dos interesses de seus gestores e de seus stakeholders, representados por grupos que possam afetar ou ser afetados pelo alcance dos objetivos da empresa. Seguindo esta linha de raciocínio, as organizações devem ser responsáveis com seus públicos de interesse (stakeholders).

Consoantes à abordagem de Carrol $(1979,1991)$, Matten e Moon (2008) apresentam uma proposta para a compreensão da responsabilidade social corporativa a partir de duas di- 
mensões: a responsabilidade social "implícita" e "explícita". A responsabilidade social de forma implícita está alicerçada em sistemas mandatórios. Não é concebida como uma decisão voluntária e deliberada das organizações, mas sim como uma decisão reativa, reflexo de um ambiente institucional (MATTEN e MOON, 2008). Trata-se, assim de diretrizes legais e regulamentais mínimas, por parte da organização, que definem as suas obrigações para com seus stakeholders.

Por outro lado, a responsabilidade social explícita está associada às políticas corporativas que visam interesses da sociedade, consistindo em estratégias que combinem valor social e de negócios e abordem questões percebidas como sendo parte da responsabilidade social da organização (MATTEN e MOON, 2008). Os autores enfatizam que a RSC explícita reflete políticas e práticas realizadas por iniciativa da organização e não apenas aquelas impostas por instituições legais e governamentais. Sendo, assim, uma atitude voluntária, deliberada, e até mesmo estratégica, por parte da organização.

Em uma perspectiva estratégica, Galbreath (2009) faz importantes considerações no que tange à incorporação da RSC à estratégia corporativa, possibilitando o alcance de vantagens competitivas por parte das organizações. Nesse sentido, o autor afirma que a integração da RSC à estratégia organizacional pressupõe que uma incorporação depare-se com seis grandes dimensões: missão, assuntos estratégicos, mercados, necessidades dos clientes, recursos da empresa e vantagem competitiva. Assim, para Galbreath (2009), todas as ações relacionadas à responsabilidade social corporativa devem estar alinhadas às perspectivas estratégicas, não devendo existir fora do escopo destas. Subjacente a tais pressupostos encontra-se a ideia de que a responsabilidade social corporativa não deve ser vista apenas como uma forma de a empresa assumir responsabilidades perante a sociedade ou aos stakeholders, mas deve ser tratada dentro das dimensões fundamentais da estratégia.

Ao longo das últimas décadas, a Responsabilidade Social Corporativa tornou-se cada vez mais importante como foco estratégico nos locais de trabalho. As organizações têm respondido às novas demandas sociais, de seus grupos de interesse, através da implementação de ações de RSC, rompendo a imagem tradicional de que uma empresa concentra-se unicamente na geração de valor econômico para seus stakeholders, a partir da inclusão de atividades ambientais e sociais (FUENTES-GARCIA et al., 2007).

Considerando diferentes stakeholders, a literatura sugere que as ações de RSC podem ser classificadas como externas e internas (Rodrigo e Arenas, 2008). As externas tem foco na comunidade, por meio de ações sociais. Em relação à dimensão interna, as interações entre a organização e seus colaboradores assumem um papel central nos estudos sobre a temática, destacando-se o papel da Gestão de Pessoas na implementação de práticas de RSC.

\subsection{Interações entre Responsabilidade Social Corporativa e Gestão de Pessoas}

As pressões sobre as organizações, para a adoção de comportamentos responsáveis, têm demandado reais e importantes alterações em suas atividades diárias, cultura e estruturas organizacionais, de modo a tornar a responsabilidade social corporativa como uma das atividades centrais (Maon e Swaen, 2009), tanto a nível interno como externo. Internamente, essa centralidade está associada às práticas que vislumbrem os interesses do público interno, considerado como um grupo de atores primários, identificados como partes interessadas que a empresa tem o dever de atender (GREENWOOD, 2007).

A preocupação com o desenvolvimento de políticas e práticas de responsabilidade social corporativa, que envolva o público interno, tem se mostrado como um fator de extrema importância para as empresas que desejam tornarem-se sustentáveis, uma vez que pressupõe uma mudança nos princípios de gestão organizacional. Nesta mesma linha de entendimento, Venson 
et al. (2013) sublinha que, em um cenário organizacional permeado por constantes e intensas mudanças nas estruturas gerenciais, o fator humano torna-se um elemento diferenciador das organizações, o que requer atenção especial das empresas.

Sob este aspecto, a Responsabildade Social Corporativa envolve o bem-estar dos colaboradores, práticas éticas de gestão, políticas de não discriminação no local de trabalho, justiça, educação e desenvolvimento profissional (WELFORD, 2004). No entanto, apesar de sua importância, as práticas de RSC, direcionadas ao público interno, mantiveram-se em grande parte negligenciadas (KIM et al., 2010).

Nesse sentido, a Gestão de Pessoas assume um papel relevante na disseminação de práticas sustentáveis, ao priorizar ações de RSC com o público interno. Sob essas perspectivas, autores como Longo et al. (2005), Papasolomou et al., (2005) e Turker (2009), considerando a Teoria dos Stakeholders, ressaltam a relevância de tais práticas, e destacam algumas ações de RSC com o público interno, descritas no Quadro 1.

\begin{tabular}{|c|l|}
\hline Autores & \multicolumn{1}{|c|}{ RSC com o público interno } \\
\hline Longo et al. (2005) & $\begin{array}{l}\text { Saúde e segurança no trabalho } \\
\text { Desenvolvimento de competências dos trabalhadores } \\
\text { Bem-estar e satisfação do trabalhador } \\
\text { Qualidade do trabalho } \\
\text { Equidade social }\end{array}$ \\
\hline Papasolomou et \\
al. (2005) & $\begin{array}{l}\text { Bom ambiente de trabalho } \\
\text { Restão responsável dos recursos humanos } \\
\text { Recomunicação aberta e flexível com os colaboradores } \\
\text { Desenvolvimento dos colaboradores } \\
\text { Liberdade de expressão } \\
\text { Suporte além do que é esperado por lei } \\
\text { Diversidade na contratação e promoção de mulheres, minorias étnicas e deficientes } \\
\text { físicos. } \\
\text { Tratamento digno e justo a todos os funcionários }\end{array}$ \\
\hline Autores & RSC com o público interno \\
\hline Turker (2009) & $\begin{array}{l}\text { Incentivo ao desenvolvimento de competências e carreira dos colaboradores } \\
\text { Gestão preocupada com as necessidades e expectativas dos trabalhadores } \\
\text { Implementação de políticas flexíveis para proporcionar boas condições de trabalho } \\
\text { e equilíbrio na vida de seus colaboradores } \\
\text { Decisões administrativas justas em relação aos colaboradores. } \\
\text { Incentivo e apoio a qualificação profissional }\end{array}$ \\
\hline
\end{tabular}

Quadro 1 - Responsabilidade Social Corporativa com o público interno

Fonte: elaborado a partir de Longo et al. (2005); Papasolomou et al.(2005); Turker (2009) e Jamali (2008).

Conforme o Quadro 1, as ações de RSC abrangem práticas associadas à área de Gestão de Pessoas. Como afirmam Fuentes-Garcia et al. (2007), um dos aspectos básicos da RSC é que também pode ser implementada dentro da própria empresa, especificamente pela área de Gestão de Pessoas. Nesse contexto, a RSC com o público interno perpassa os requisitos mínimos de respeito aos direitos dos trabalhadores, pela inclusão de políticas que garantam o equilíbrio e qualidade de vida no trabalho e a aprendizagem contínua.

Assim, empresa socialmente responsável é sinônimo de empresa humanizada, voltada para seus funcionários e para o ambiente, agregando outros valores que não somente a maximização do retorno financeiro para os acionistas (VERGARA e BRANCO, 2001). Além disso, priorizar a responsabilidade social com o público interno, diante de outros stakeholders, reflete, sob o prisma da ética, a coerência entre discurso e prática (FURTADO e PENA, 2007). 


\section{MÉTODO}

Este estudo caracteriza-se como uma pesquisa descritiva, que segundo Hair et al. (2005) consiste em um tipo de pesquisa estruturada e especificamente criada para mensurar um evento ou atividade. Quanto à abordagem, trata-se de uma pesquisa qualitativa realizada através da análise de dados secundários, coletados a partir de duas pesquisas brasileiras sobre Sustentabilidade, RSC e Gestão de Pessoas, realizadas pela Revista Exame: o "Guia Exame de Sustentabilidade" e o Guia "Melhores Empresas para Trabalhar", de 2006 a 2011.

A Revista Exame foi escolhida como fonte de dados, para este estudo, uma vez que é um periódico nacional de grande circulação e confiabilidade. Constatou-se a utilização destas publicações em estudos anteriores, interessados em comportamentos relativos à Sustentabilidade e à Gestão de Pessoas, como nas pesquisas desenvolvidas por Morais Neto, Pereira e Maccari (2012) e Tolfo e Piccini (2011).

Ambos os guias tem como objetivo nomear, por meio de um ranking, as empresas que são referências nas áreas de sustentabilidade e Gestão de Pessoas. A participação das empresas é feita por meio de uma candidatura, e posteriormente a aplicação de uma metodologia específica para cada um dos guias. O Guia Exame de Sustentabilidade busca determinar as referências na área, com base em um questionário, que abrangem as práticas de gestão, acompanhadas de uma análise qualitativa realizada por especialistas da área. A publicação "Melhores Empresas para Trabalhar" é tida como uma pesquisa de clima organizacional, que busca através de índices e indicadores, associados a um laudo técnico de especialistas, traçar as referências em Gestão de Pessoas no país, a partir de categorias como: cidadania empresarial, estratégia e gestão, carreira, desenvolvimento, liderança, saúde e remuneração.

Ressalta-se que a definição do período inicial de análise, deve-se as mudanças ocorridas em 2006 no Guia Exame de Sustentabilidade, anteriormente denominado de Guia Exame de Boa Cidadania Corporativa. A partir de 2006, as ações relatadas pelas organizações passaram por novos critérios de avaliação, a fim de selecionar os projetos em destaque (empresas modelo). As mudanças no guia apoiaram-se em uma nova metodologia elaborada pelo Centro de Estudos em Sustentabilidade da Fundação Getúlio Vargas de São Paulo, o que possibilitou um maior detaIhamento das ações selecionadas, através da análise de diversos aspectos da sustentabilidade, como as dimensões sociais e ambientais e econômico-financeiras.

Para a coleta de dados utilizou-se da análise documental, através da consulta do site da revista Exame e dos guias Exame de Sustentabilidade e Melhores Empresas para Trabalhar. A coleta e análise dos dados foram realizadas através das categorias descritas no Quadro 2.

\begin{tabular}{|l|l|}
\hline Empresa & Nome; Setor; Região \\
\hline \multirow{4}{*}{ RSC } & Periodicidade no Guia Exame de Sustentabilidade \\
\cline { 2 - 2 } & Práticas de responsabilidade social corporativa \\
\hline \multirow{4}{*}{ Perfil } & Número de funcionários \\
\cline { 2 - 2 } & $\%$ de Homens e Mulheres \\
\cline { 2 - 2 } & Idade Média dos Colaboradores \\
\cline { 2 - 2 } & Tempo Médio de Empresa \\
\hline Gestão de Pessoas & Práticas de gestão de pessoas \\
\hline
\end{tabular}

Quadro 2 - Categorias analíticas e itens investigados

Fonte: elaborado pelos autores.

Inicialmente, foi realizado um levantamento das empresas modelo, indicadas no Guia Exame de Sustentabilidade no período de 2006 a 2011, totalizando 48 empresas. Após esta etapa, buscaram-se identificar quais destas empresas constavam no Guia Melhores Empresas para Trabalhar, 
no mesmo período, sendo constatadas 25 empresas, consideradas objeto de análise deste estudo.

Para fins de classificação, das práticas de responsabilidade social corporativa, optou-se por utilizar uma adaptação da abordagem de Sachs (2002), considerando as dimensões social/ cultural e ambiental/ecológica, sem incluir as dimensões políticas, territoriais e econômicas, as quais não são contempladas em sua totalidade nos referidos guias. Para melhor compreensão, a Figura 1 apresenta uma síntese do modelo de pesquisa realizado neste estudo.

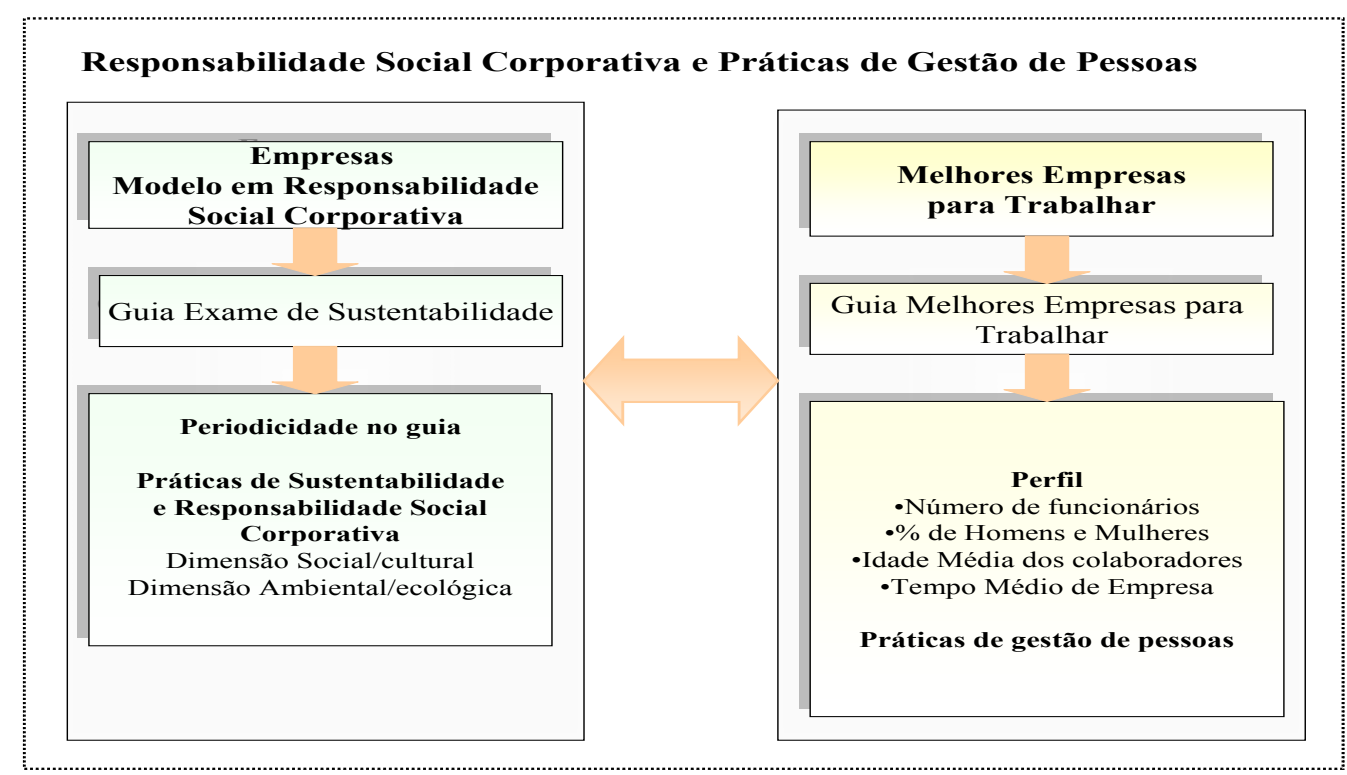

Figura 1 - Desenho de pesquisa

Fonte: elaborado pelos autores da pesquisa.

Assim, as categorias de análise do referido modelo correspondem às práticas de Sustentabilidade e Responsabilidade Social Corporativa, considerando as dimensões Social/cultural e Ambiental/ecológica e as práticas de gestão de pessoas identificadas nas empresas analisadas.

Após os procedimentos de coleta das informações das empresas investigadas, realizouse o tratamento e interpretação dos dados qualitativos, através da análise de conteúdo, que segundo Bardin (2011), abrange as iniciativas de explicitação, sistematização e expressão do conteúdo evidente da comunicação, com a finalidade de se efetuarem deduções lógicas e justificadas a respeito da origem das mensagens. Ainda, realizou-se a análise descritiva dos dados quantitativos, através dos cálculos de frequência. Para a realização de tais cálculos, com o auxílio do software Excel, os dados obtidos no período de 2006 a 2011 (dados de perfil e práticas de Sustentabilidade e Responsabilidade Social Corporativa e Gestão de Pessoas) foram elencados e quantificados.

\section{ANÁLISE DOS RESULTADOS}

A partir da análise das empresas modelo em Responsabilidade Social Corporativa divulgada no Guia Exame de Sustentabilidade no período de 2006 a 2011, chegou-se ao total de 48 empresas. Destas, 25 (52,1\%) foram também consideradas, no respectivo período, como melhores empresas para trabalhar (Guia Melhores Empresas para Trabalhar), sendo objeto de análise no presente estudo. A Tabela 1 apresenta o perfil destas empresas. 
Tabela 1: Perfil das empresas

\begin{tabular}{|c|c|c|c|}
\hline Categorias & Variáveis & \begin{tabular}{|c|} 
No de \\
empresas
\end{tabular} & Percentual \\
\hline $\begin{array}{l}\text { Periodicidade no Guia de } \\
\text { Sustentabilidade e Melho- } \\
\text { res Empresas para Traba- } \\
\text { Ihar }\end{array}$ & \begin{tabular}{|l}
1 ano \\
2 anos \\
3 anos \\
4 anos \\
5 anos \\
6 anos
\end{tabular} & $\begin{array}{l}14 \\
3 \\
3 \\
3 \\
1 \\
1 \\
\end{array}$ & \begin{tabular}{|l|}
$56 \%$ \\
$12 \%$ \\
$12 \%$ \\
$12 \%$ \\
$4 \%$ \\
$4 \%$ \\
\end{tabular} \\
\hline Setor & $\begin{array}{l}\text { Indústria } \\
\text { Serviço }\end{array}$ & $\begin{array}{l}16 \\
9\end{array}$ & $\begin{array}{l}64 \% \\
36 \% \\
\end{array}$ \\
\hline Região do país & $\begin{array}{l}\text { Nordeste } \\
\text { Sudeste } \\
\text { Sul }\end{array}$ & $\begin{array}{l}1 \\
20 \\
4\end{array}$ & \begin{tabular}{|l|}
$4 \%$ \\
$80 \%$ \\
$16 \%$ \\
\end{tabular} \\
\hline Número de funcionários & $\begin{array}{l}200 \text { a } 1000 \text { funcionários } \\
10001 \text { a } 2000 \text { funcionários } \\
2001 \text { a } 5000 \text { funcionários } \\
5001 \text { a } 10000 \text { funcionários } \\
\text { Mais de } 10000 \text { funcionários }\end{array}$ & $\begin{array}{l}4 \\
2 \\
9 \\
5 \\
5\end{array}$ & \begin{tabular}{|l|}
$16 \%$ \\
$8 \%$ \\
$36 \%$ \\
$20 \%$ \\
$20 \%$ \\
\end{tabular} \\
\hline $\begin{array}{l}\text { Percentual de homens e } \\
\text { mulheres }\end{array}$ & $\begin{array}{l}\text { Maior percentual de homens } \\
\text { Maior percentual de mulheres } \\
\text { Percentual semelhante de homens e mulheres }\end{array}$ & $\begin{array}{l}21 \\
3 \\
1 \\
\end{array}$ & \begin{tabular}{|l|}
$84 \%$ \\
$12 \%$ \\
$4 \%$ \\
\end{tabular} \\
\hline $\begin{array}{l}\text { Idade média dos colabora- } \\
\text { dores }\end{array}$ & $\begin{array}{l}30 \text { a } 35 \text { anos } \\
36 \text { a } 40 \text { anos } \\
41 \text { a } 45 \text { anos }\end{array}$ & $\begin{array}{l}13 \\
11 \\
1 \\
\end{array}$ & $\begin{array}{l}52 \% \\
44 \% \\
4 \% \\
\end{array}$ \\
\hline Tempo médio de serviço & $\begin{array}{l}0 \text { a } 5 \text { anos } \\
6 \text { a } 10 \text { anos } \\
11 \text { a } 15 \text { anos } \\
16 \text { a } 20 \text { anos }\end{array}$ & $\begin{array}{l}3 \\
9 \\
11 \\
2\end{array}$ & $\begin{array}{l}12 \% \\
36 \% \\
44 \% \\
8 \% \\
\end{array}$ \\
\hline
\end{tabular}

Fonte: elaborado pelos autores com base nos dados da pesquisa.

Em relação à periodicidade, no Guia de Sustentabilidade e Melhores Empresas para Trabalhar, pode-se constatar que a maioria das empresas (56\%) foi mencionada apenas em um dos anos da publicação, em ambas as pesquisas, sendo que somente uma empresa foi designada modelo em sustentabilidade, RSC e Gestão de Pessoas nos seis anos do estudo. Esta empresa atua nos setores químico, petroquímico, de engenharia e infraestrutura.

A maioria das empresas pesquisadas pertence ao setor industrial (64\%), desenvolvendo suas atividades principalmente na região sudeste do país (80\%), incluindo os estados de São Paulo, Rio de Janeiro, Minas Gerais e Espírito Santo. Destacando-se os setores químicos, petroquímicos e de fabricação de máquinas, motores e veículos pesados.

Em relação ao número de funcionários, constatou-se que todas as empresas possuem mais de 200 colaboradores, predominando organizações com 2001 a 5000 funcionários (36\%). Esses dados sugerem que as empresas de maior porte possuem ações de sustentabilidade e gestão de pessoas formalizadas e disseminadas publicamente, o que pode estar relacionado também às exigências e fiscalizações legais e ambientais, as quais essas organizações estão expostas.

Quanto ao percentual de homens e mulheres, constatou-se que na maioria das empresas pesquisadas há maior incidência de colaboradores do sexo masculino (84\%). Tal constatação pode estar associada ao predomínio do setor industrial, entre as empresas investigadas, caracterizado pelo maior número de colaboradores do sexo masculino, especialmente na indústria de transformação (GUIMARÃES, 2004).

Em relação à idade, observou-se a média de 36 anos, havendo maior concentração de colaboradores na faixa etária de 30 a 35 anos (52\%). Constatou-se também, o tempo médio de serviço de 12 anos, havendo o predomínio de colaboradores que atuam entre 11 a 15 anos na 
empresa (44\%). Esses dados sugerem que nas organizações modelo em sustentabilidade, RSC e melhores empresas para trabalhar há certa estabilização do quadro funcional, já que a maioria dos funcionários está na empresa por significativo período de tempo.

\subsection{Práticas de RSC e Gestão de Pessoas no período de 2006 a 2011}

Visando analisar as práticas de Responsabilidade Social Corporativa, associadas às dimensões Social/cultural e Ambiental/ecológica e Gestão de Pessoas, foram destacadas as principais ações desenvolvidas pelas organizações no período analisado na Tabela 2. As práticas de menor expressividade foram agrupadas na categoria "outros".

Tabela 2 - Práticas de Responsabilidade Social Corporativa

\begin{tabular}{|c|c|c|c|c|}
\hline Ano & Práticas RSC Dimensão Social/cultural & Percentual & $\begin{array}{l}\text { Práticas RSC Dimensão } \\
\text { Ambiental/ecológica }\end{array}$ & Percentual \\
\hline \multirow{5}{*}{2006} & Qualidade de vida no trabalho & $30 \%$ & Uso de materiais recicláveis & $38 \%$ \\
\hline & Interações com a comunidade & $15 \%$ & Gestão de resíduos & $25 \%$ \\
\hline & Incentivo ao trabalho voluntário & $15 \%$ & Arborização urbana & $13 \%$ \\
\hline & Projetos culturais & $15 \%$ & $\begin{array}{l}\text { Preservação da fauna e da } \\
\text { flora }\end{array}$ & $8 \%$ \\
\hline & Outros & $25 \%$ & Outros & $16 \%$ \\
\hline \multirow{5}{*}{2007} & $\begin{array}{l}\text { Apoio a educação do público interno e } \\
\text { externo }\end{array}$ & $38 \%$ & $\begin{array}{c}\text { Preservação dos recursos } \\
\text { hídricos }\end{array}$ & $32 \%$ \\
\hline & Desenvolvimento local & $25 \%$ & Produção limpa & $24 \%$ \\
\hline & Qualidade de vida no trabalho & $13 \%$ & Uso de materiais recicláveis & $20 \%$ \\
\hline & Incentivo ao trabalho voluntário & $13 \%$ & Reflorestamento e arborização & $12 \%$ \\
\hline & Outros & $13 \%$ & Outros & $12 \%$ \\
\hline \multirow{5}{*}{2008} & Incentivo ao trabalho voluntário & $25 \%$ & Produção limpa & $22 \%$ \\
\hline & $\begin{array}{l}\text { Apoio a educação do público interno e } \\
\text { externo }\end{array}$ & $25 \%$ & $\begin{array}{c}\text { Preservação dos recursos hí- } \\
\text { dricos }\end{array}$ & $21 \%$ \\
\hline & Apoio a diversidade e inclusão social & $19 \%$ & Preservação da fauna e flora & $21 \%$ \\
\hline & Desenvolvimento local & $13 \%$ & Uso de materiais recicláveis & $14 \%$ \\
\hline & Outros & $19 \%$ & Outros & $22 \%$ \\
\hline Ano & Práticas RSC Dimensão Social/cultural & Percentual & $\begin{array}{c}\text { Práticas RSC Dimensão Am- } \\
\text { biental/ecológica }\end{array}$ & Percentual \\
\hline \multirow{5}{*}{2009} & $\begin{array}{c}\text { Apoio à educação do público interno e } \\
\text { externo }\end{array}$ & $38 \%$ & $\begin{array}{l}\text { Redução no uso de água e } \\
\text { energia }\end{array}$ & $33 \%$ \\
\hline & Benefícios sociais & $23 \%$ & Reciclagem de lixo & $27 \%$ \\
\hline & Incentivo a projetos sustentáveis & $15 \%$ & $\begin{array}{l}\text { Análise dos riscos ambientais } \\
\text { de um projeto }\end{array}$ & $13 \%$ \\
\hline & Ações para diminuir o trabalho infantil & $8 \%$ & Redução dos gases tóxicos & $7 \%$ \\
\hline & Outros & $15 \%$ & Outros & $20 \%$ \\
\hline \multirow{5}{*}{2010} & Incentivo a projetos sustentáveis & $37 \%$ & $\begin{array}{l}\text { Investimentos em ações de } \\
\text { educação ambiental }\end{array}$ & $37 \%$ \\
\hline & $\begin{array}{c}\text { Apoio a educação do público interno e } \\
\text { externo }\end{array}$ & $26 \%$ & Uso de materiais recicláveis & $21 \%$ \\
\hline & Desenvolvimento local & $16 \%$ & $\begin{array}{c}\text { Redução no uso de água e } \\
\text { energia }\end{array}$ & $10 \%$ \\
\hline & $\begin{array}{l}\text { Participação na elaboração de políticas } \\
\text { públicas }\end{array}$ & $11 \%$ & Preservação da fauna e flora & $11 \%$ \\
\hline & Outros & $11 \%$ & Outros & $21 \%$ \\
\hline
\end{tabular}




\begin{tabular}{c|c|c|c|c}
\hline Ano & Práticas RSC Dimensão Social/cultural & Percentual & $\begin{array}{c}\text { Práticas RSC Dimensão } \\
\text { Ambiental/ecológica }\end{array}$ & Percentual \\
\hline \multirow{2011}{*}{$\begin{array}{c}\text { Capacitação de funcionários } \\
\text { Eliminação de discriminação relaciona- } \\
\text { da ao emprego }\end{array}$} & $42 \%$ & $\begin{array}{c}\text { Utilização de energias } \\
\text { renováveis } \\
\text { Apoio a educação do público interno e } \\
\text { externo }\end{array}$ & $\begin{array}{c}\text { Redução no uso de água e } \\
\text { energia }\end{array}$ & $42 \%$ \\
& $\begin{array}{c}\text { Seleção e avaliação de fornecedores } \\
\text { Outros }\end{array}$ & $8 \%$ & $\begin{array}{c}\text { Evitar desperdício } \\
\text { Análise dos riscos ambientais } \\
\text { de um projeto }\end{array}$ & $\begin{array}{c}25 \% \\
\text { Outros }\end{array}$ \\
\hline
\end{tabular}

Fonte: elaborado pelos autores com base nos dados da pesquisa.

Em relação às práticas de RSC associadas à dimensão Social/cultural, a Tabela 2 evidencia que estas apresentaram oscilações e variações durante o período de tempo analisado.

No ano de 2006, a prática Qualidade de Vida no Trabalho apresentou o maior percentual entre as organizações investigadas (30\%), havendo um decréscimo no ano seguinte, representando $13 \%$ das práticas prioritárias dessas empresas, não sendo destacada como foco nos outros anos analisados. Da mesma forma, a prática: Incentivo ao trabalho voluntário apresentou expressividade nos anos de 2006, 2007 e 2008 e não obteve representatividade nos demais anos.

Entre as práticas de maior representatividade no período analisado, destaca-se o Apoio à educação do público interno e externo, a qual predominou nos anos de 2007, 2008 e 2009, mantendo-se em destaque também nos anos de 2010 e 2011. Ressalta-se também, que no ano de 2011 houve o enfoque para as práticas Capacitação dos funcionários (42\%) e Eliminação da discriminação relacionada ao emprego (17\%), que não haviam sido priorizadas diretamente nos anos anteriores.

As práticas prioritárias no período analisado revelam haver interesse das organizações em manter uma interação com a sociedade, havendo maior preocupação com aspectos relacionados ao desenvolvimento dos colaboradores e das comunidades locais. Tais indicadores sugerem que subjacente à noção de responsabilidade social corporativa está o entendimento de que organizações e sociedade são atores entrelaçados e não entidades distintas (WOOD, 1991), o que implica uma interação contínua entre estes.

No entanto, percebe-se também haver algumas limitações, quanto às práticas associadas à diversidade, na contratação e promoção de mulheres, minorias étnicas, tratamento justo, equidade social e de gênero (PAPASOLOMOU et al., 2005; LONGO et al., 2005), as quais restringiram-se ao Apoio a diversidade e inclusão social (2008) e Eliminação da discriminação relacionada ao emprego (2011). Essa constatação sugere haver espaço para ampliação das práticas de RSC, que vislumbrem aspectos relacionados à equidade e justiça, considerando seus múltiplos aspectos. Como afirma Van Marrewijk (2003), tanto no meio acadêmico quanto no mundo dos negócios, parece existir um consenso acerca do fato de que as organizações devem buscar formas mais transparentes, humanas e éticas de conduzir seus negócios.

A dimensão ambiental/ecológica representa um real desafio aos gestores no desenvolvimento e adoção de estratégias, que vão desde a concepção do produto até o seu descarte (VITHESSONTI, 2009), ou seja, pressupõe a interligação de toda a cadeia de forma proativa. Desta forma, é de suma importância a implantação de uma gestão ambiental que trace padrões de metas ambientais/ecológicas, desenvolvendo práticas de gestão que visem conciliar ganhos econômicos e responsabilidades ambientais. Neste sentido, algumas destas práticas incluem reciclagem, busca de matérias-primas e processos produtivos de menor impacto ambiental, passando a racionalizar o uso dos recursos naturais renováveis e não renováveis e tecnologias de produção mais limpa - end of pipe - entre outros. 
Quanto às práticas de RSC associadas à dimensão Ambiental/ecológica, as principais ações desenvolvidas pelas organizações pesquisadas também evidenciaram variações durante o período analisado. A prática de maior representatividade refere-se ao uso de materiais recicláveis, mencionada nos anos de 2006, 2007, 2008 e 2010.

No ano de 2006, essa prática destaca-se como sendo a de maior representatividade, (38\%). Contudo, nos anos de 2007, 2008, 2009 e 2010, há um decréscimo. A utilização de materiais recicláveis abrange uma gama de ações, que vão desde o uso de materiais de escritório em empresas de serviços, até mesmo matérias-primas, como por exemplo, o uso de concreto na indústria de construção. Assim, o emprego, estratégico ou não desta prática, e sua amplitude, carece de maior investigação.

O emprego deste tipo de prática por parte da empresa, seja de uma forma mais ousada ou conservadora, pressupõe uma redução dos custos econômicos e impactos ambientais, quanto pode vir a proporcionar ganhos de produtividade, competitividade e lucratividade. Sob essa mesma ótica, Korhonen, Wihersaari e Savolainen (2001) sugerem o desenvolvimento de sistemas industriais, de modo que o uso de matérias-primas seja mantido de acordo com a sua capacidade de renovação, limitando o uso de recursos não renováveis.

No período analisado, as práticas ambientais/ecológicas associadas à preservação da fauna e da flora e redução de gases tóxicos também apresentaram expressividade. Sobre a última, convém salientar, trata-se de uma prática específica para determinados setores industriais, devido às regulamentações legais para o tratamento deste tipo de resíduo.

Outro item, que merece destaque, refere-se à análise de risco ambiental de projetos. Esta prática aparece em evidência nos anos de 2009 e 2011. Observa-se que, no ano de 2011, último período analisado, a prática da dimensão ambiental/ecológica de maior destaque foi a Utilização de Energias Renováveis (42\%), embora a mesma não tivesse obtido destaque nos demais períodos analisados. No caso brasileiro, o apoio governamental nos últimos anos tem sido determinante para adoção e utilização de fontes alternativas de energia, principalmente no caso das indústrias (BARTON, 2011; PEREIRA JR et al. 2008). Muito embora ainda o setor careça de investimentos e tecnologias, o avanço na utilização de energias renováveis tem sido notável no país.

Em relação às práticas de Gestão de Pessoas das organizações modelo em RSC e melhores empresas para trabalhar, podem ser visualizadas na Tabela 3.

Tabela 3 - Práticas de Gestão de Pessoas

\begin{tabular}{c|l|c}
\hline Ano & Práticas de Gestão de Pessoas & Percentual \\
\hline \multirow{2}{*}{2006} & Plano de carreira e desenvolvimento & $36,4 \%$ \\
& Benefícios Sociais & $31,8 \%$ \\
& Saúde e segurança no trabalho & $9,1 \%$ \\
& Programa de participação nos lucros/resultados & $9,1 \%$ \\
& Outros & $13,6 \%$ \\
\hline \multirow{2}{*}{2007} & Plano de carreira e desenvolvimento & $35,6 \%$ \\
& Benefícios sociais & $28,9 \%$ \\
& Desenvolvimento gerencial & $17,8 \%$ \\
& Programa de participação nos lucros/resultados & $8,9 \%$ \\
& Outros & $8,9 \%$ \\
\hline
\end{tabular}




\begin{tabular}{|c|c|c|}
\hline Ano & Práticas de Gestão de Pessoas & Percentual \\
\hline 2008 & $\begin{array}{l}\text { Plano de carreira e desenvolvimento } \\
\text { Benefícios sociais } \\
\text { Qualidade de vida no trabalho } \\
\text { Treinamento e desenvolvimento } \\
\text { Outros }\end{array}$ & $\begin{array}{l}27,3 \% \\
22,7 \% \\
18,2 \% \\
13,6 \% \\
18,2 \%\end{array}$ \\
\hline Ano & Práticas de Gestão de Pessoas & Percentual \\
\hline 2009 & $\begin{array}{l}\text { Treinamento e desenvolvimento } \\
\text { Comunicação interna } \\
\text { Plano de carreira e desenvolvimento } \\
\text { Benefícios sociais } \\
\text { Outros }\end{array}$ & $\begin{array}{l}31,6 \% \\
21,1 \% \\
15,8 \% \\
10,5 \% \\
21,1 \%\end{array}$ \\
\hline 2010 & $\begin{array}{l}\text { Qualidade de vida no trabalho } \\
\text { Desenvolvimento gerencial } \\
\text { Benefícios sociais } \\
\text { Treinamento e desenvolvimento } \\
\text { Outros }\end{array}$ & $\begin{array}{c}38,1 \% \\
23,8 \% \\
14,3 \% \\
9,5 \% \\
14,3 \%\end{array}$ \\
\hline 2011 & $\begin{array}{l}\text { Plano de carreira e desenvolvimento } \\
\text { Desenvolvimento gerencial } \\
\text { Treinamento e desenvolvimento } \\
\text { Qualidade de vida no trabalho } \\
\text { Outros }\end{array}$ & $\begin{array}{l}31,6 \% \\
21,1 \% \\
15,8 \% \\
10,5 \% \\
21,1 \% \\
\end{array}$ \\
\hline
\end{tabular}

Fonte: elaborado pelos autores com base nos dados da pesquisa.

Quanto às práticas de Gestão de Pessoas, a Tabela 3 demonstra que houve poucas variações durante o período analisado. As iniciativas com maior representatividade estão associadas à existência do Plano de Carreira e Desenvolvimento e Benefícios Sociais, as quais foram destaque em cinco anos analisados. As práticas associadas ao Treinamento e Desenvolvimento e Desenvolvimento Gerencial também foram priorizadas por essas organizações.

O predomínio dessas práticas sugere que o foco da gestão de pessoas das organizações, consideradas modelo em sustentabilidade e melhores empresas para trabalhar, priorizam aspectos mais específicos da área (Lengnick-Hall et al., 2009), demonstrando o interesse das empresas em contribuir com o desenvolvimento e qualificação dos indivíduos, bem como fornecer subsídios para ascensão de suas carreiras. No entanto, deve-se ponderar que mesmo priorizando estes aspectos, tais práticas podem sinalizar a preocupação com questões estratégicas, associadas ao alinhamento das práticas de gestão de pessoas da organização. Considera-se, entretanto, que a ampliação destas análises exige um aprofundamento acerca de tais práticas, que não estão contempladas nos objetivos deste trabalho.

\subsection{Panorama das Práticas de RSC e Gestão de Pessoas}

Com a intenção de proporcionar a melhor visualização das práticas de RSC e gestão de pessoas, considerando também o setor de atuação das organizações modelo em sustentabilidade, responsabilidade social corporativa e melhores empresas para trabalhar, optou-se por apresentar um panorama das práticas predominantes no período investigado. A Figura 2 ilustra tais prioridades. 


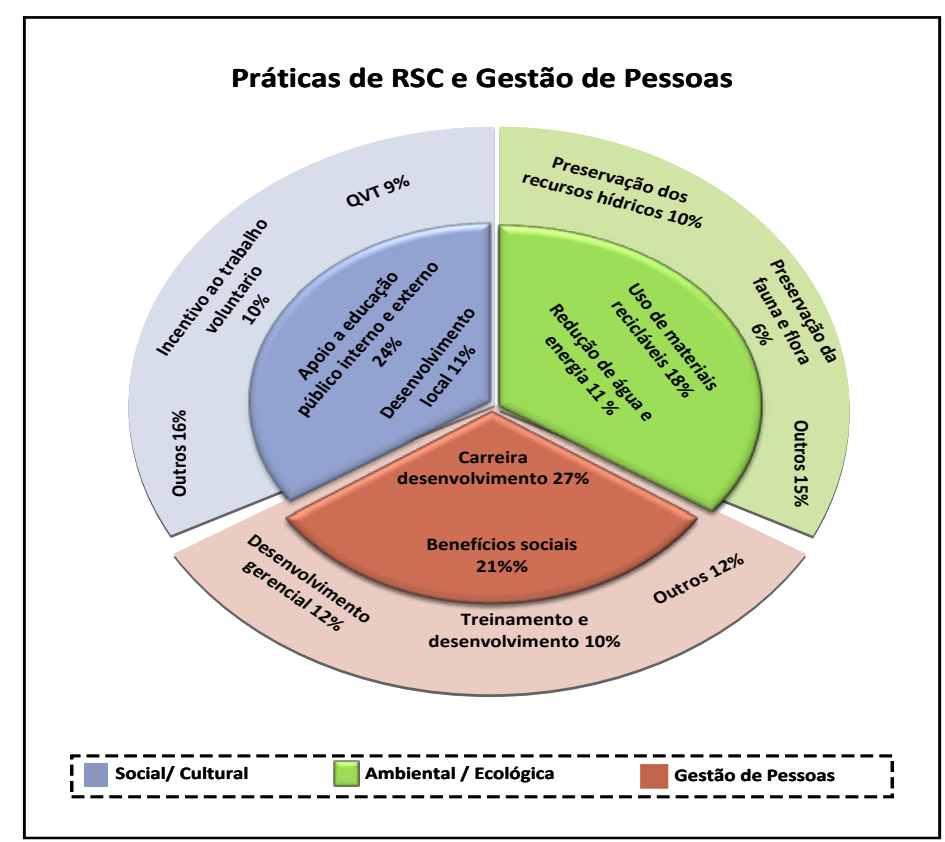

Figura 2 - Práticas de RSC e Gestão de Pessoas no período de 2006 a 2011 Fonte: elaborado pelos autores com base nos dados da pesquisa.

Como salientam Morais Neto, Pereira e Maccari (2012), é importante que exista uma distribuição igualitária das ações empresariais entre os diversos temas da sustentabilidade ao invés de concentrar atitudes em apenas algumas dimensões. Em relação às práticas associadas à dimensão Social/cultural pode-se constatar a maior preocupação com o apoio à educação do público interno e externo, desenvolvimento local, incentivo ao trabalho voluntário e qualidade de vida. Em alguns países subdesenvolvidos e em desenvolvimento, como é o caso do Brasil, as organizações muitas vezes vêm a desempenhar o papel do Estado, enquanto provêm uma infraestrutura mínima, em apoio à educação e ao desenvolvimento local, nas comunidades onde se situam. Nestas condições, muitas vezes o papel das organizações se confunde com o do Estado e a responsabilidade social destas passa a ser ampliada.

No que tange a responsabilidade social corporativa, relacionada à dimensão ambiental/ecológica, pode-se perceber que há o predomínio de ações associadas ao uso de materiais recicláveis, seguido de práticas de redução de água e energia. O predomínio de tais práticas demonstra que as empresas elencadas nestes relatórios tratam esta dimensão de forma geral. Observa-se que as práticas de maior destaque estão centradas na redução, seja de consumo de energia, seja de matérias-primas ou materiais (através da utilização de materiais recicláveis), enquanto que as práticas de menor representatividade estão relacionadas à preservação (no caso, de recursos hídricos e da fauna e flora). Estes resultados demonstram que, no que concerne à dimensão ambiental/ecológica, a mentalidade empresarial das organizações, que contemplam os relatórios pesquisados, encontra-se focada na resolução de problemas do presente.

As práticas de Gestão de Pessoas, priorizadas pelas organizações investigadas, sinalizam ações mais específicas da área, como carreira e desenvolvimento de benefícios sociais, havendo necessidade de ampliar o enfoque da área para uma dimensão mais estratégica e comportamental e ética.

Ao considerar as práticas de RSC e de Gestão de Pessoas das organizações do setor industrial e de serviços, pode-se constatar algumas distinções, como se visualiza na Figura 3. 


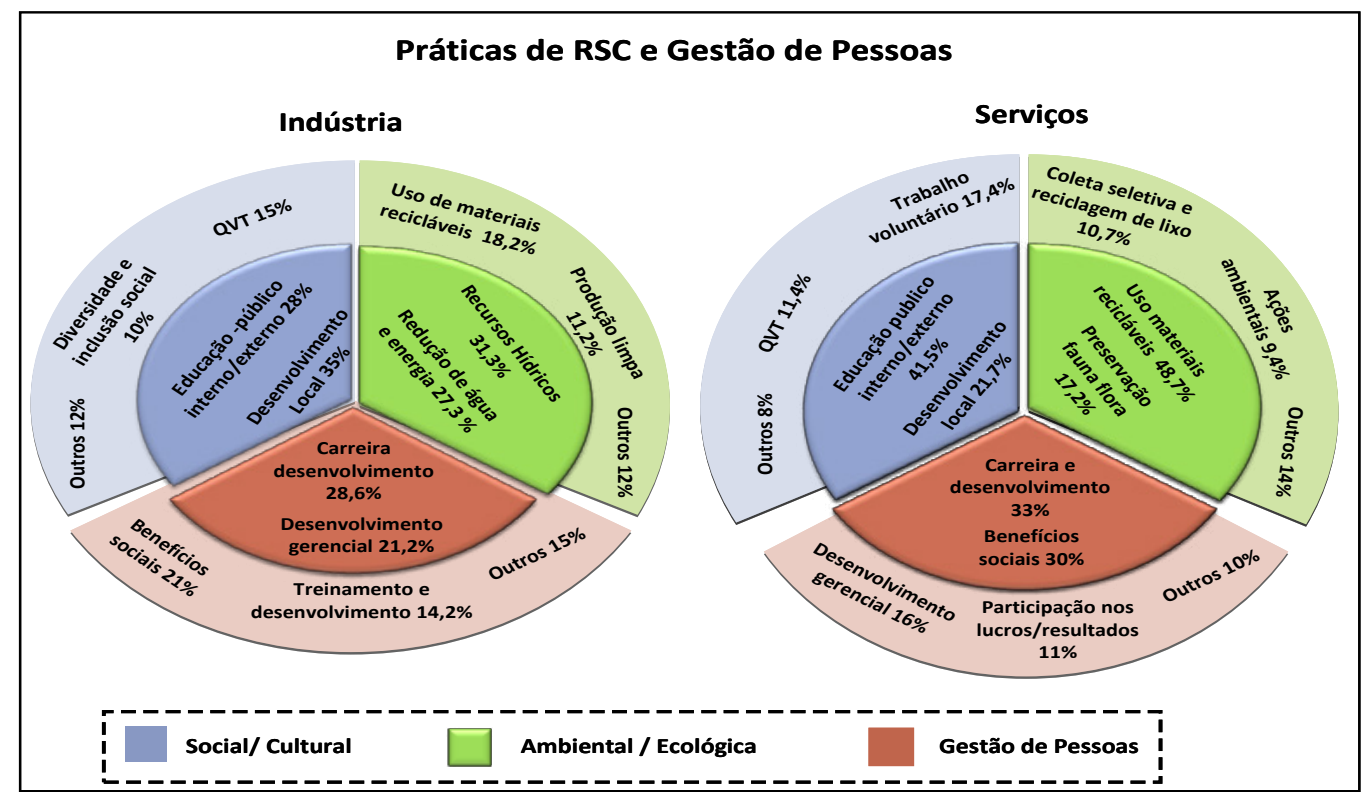

Figura 3 - Práticas de RSC e Gestão de Pessoas em organizações industriais e prestadoras de serviços Fonte: elaborado pelos autores com base nos dados da pesquisa.

De maneira geral, constatou-se que as empresas do setor industrial e prestação de serviços, atribuíram foco semelhante às práticas de RSC associadas à dimensão Social/cultural, priorizando o desenvolvimento local e o apoio a educação do público interno e externo. Já em relação à dimensão Ambiental/ecológica, percebeu-se que as empresas industriais, consideradas causadoras em potencial de maiores impactos socioambientais, centram suas ações na preservação dos recursos hídricos (31,3\%), e na redução no uso de água e energia (27,3\%) Por outro lado, as empresas prestadoras de serviço, que apresentam efeitos ambientais quase nulos (Tachizawa e POZO, 2007), resumiram suas estratégias de RSC associadas à dimensão ambiental-ecológica através do uso de materiais recicláveis $(48,7 \%)$ e preservação da fauna e da flora $(17,2 \%)$.

Outro aspecto que merece destaque refere-se às práticas de gestão de pessoas que, tanto nas organizações industriais quanto nas organizações prestadoras de serviço, priorizaram o Plano de carreira e desenvolvimento, o desenvolvimento gerencial e os benefícios sociais. Sinaliza-se para a necessidade de ampliar tais práticas de modo a associá-las às atividades como: diálogo, gestão participativa, valorização da diversidade e promoção da equidade (Longo et al., 2005; Papasolomou et al., 2005; Turker, 2009).

Com vista nesse resultado, infere-se que essas organizações não evidenciaram priorizar, de forma ampla, as práticas de responsabilidade social corporativa com o público interno. Essas constatações corroboram as perspectivas de Petrini e Pozzebon (2009), que poucos modelos de responsabilidade social corporativa buscam a integração com o modelo de gestão da organização, incluindo a área de gestão de pessoas, foco deste estudo.

\section{CONSIDERAÇÕES FINAIS}

No presente estudo procurou-se analisar as práticas de Responsabilidade Social Corporativa e as práticas de Gestão de Pessoas das empresas consideradas modelo em sustentabilidade, RSC e melhores empresas para trabalhar, apresentando um panorama dessas ações. Para tanto, valeu-se da perspectiva de que a empresa socialmente responsável, além de desenvolver 
ações no âmbito externo, deve priorizar ações no ambiente interno, através de práticas de gestão de pessoas que valorizem seus colaboradores.

A maioria das empresas listadas pertence ao setor industrial. Convém salientar que, a maior parte das empresas possui entre 2001 a 5000 funcionários. Esse resultado sinaliza para o fato de que, no Brasil, como tradicionalmente tem sido, os estudos sobre o tema apontam que sustentabilidade e responsabilidade social corporativa ainda estão associadas às grandes empresas.

Portanto, em um país como o Brasil, que no período de 2000 a 2011 possuía cerca de 6 milhões de micro e pequenas empresas, que representam $99 \%$ do total de empreendimentos do país (DIEESE, 2011), resultados como estes demonstram algumas preocupações. É de suma importância para a realidade nacional, que práticas de responsabilidade social corporativa passem a compor a agenda estratégica dessa grande maioria empresarial.

As análises das práticas de responsabilidade social corporativa foram divididas em duas dimensões: ambiental/ecológica e cultural/social. No que tange à dimensão ambiental/ecológica, os resultados demonstram que as práticas de maior expressividade estão relacionadas à utilização de materiais recicláveis e redução de utilização de água e energia. Embora tenham sua eficiência e eficácia reconhecida, tais medidas podem ser ampliadas, pois o contexto exige uma mudança de posicionamento, adotando um estilo gerencial proativo, que oriente desde a concepção até o descarte do produto, evitando o surgimento de problemas, a fim de reduzir os impactos ambientais.

Em relação à dimensão social/cultural, as ações com maior percentual estão voltadas ao apoio à educação e ao desenvolvimento local. Tais ações podem estar tanto associadas ao papel que grandes corporações assumem em países como o Brasil, em que muitas vezes é necessário estas proverem certa infraestrutura mínima para as comunidades onde atuam; quanto às características próprias do contexto que sugerem uma aproximação maior com os stakeholders.

De maneira geral, as práticas de Gestão de Pessoas das empresas investigadas, evidenciaram a prioridade de aspectos específicos, o que sugere a necessidade de ampliação do papel da área de gestão na disseminação de práticas de RSC, voltadas aos interesses dos colaboradores. De certo modo, as práticas de maior expressividade - carreira e desenvolvimento e benefícios sociais - estão associadas às práticas de responsabilidade social corporativa em sua dimensão social e cultural, demonstrando a interligação entre estas áreas.

É importante lembrar que, em países como o Brasil, é comum empresas fornecerem apoio à educação de seus funcionários bem como auxiliarem no desenvolvimento educacional dos membros das famílias destes, atuando na comunidade, visando o desenvolvimento local. Nestes casos, desenvolvimento local das comunidades pode ser utilizado como uma estratégia em locais onde a mão-de-obra especializada é escassa.

Este estudo possuiu como limitações o fato de valer-se apenas dos levantamentos quantitativos dos guia analisados. Uma análise mais rica deveria contemplar informações acerca do histórico e relatórios de sustentabilidade das organizações envolvidas. Assim, sugerem-se estudos futuros que avancem buscando suprir estas limitações. 


\section{REFERÊNCIAS}

BARTON, M. Energy in Brazil. International Journal of Environmental Studies, v. 68, n. 6, p. 996-997, 2011.

BARDIN, L. Análise de Conteúdo. São Paulo: Edições 70, 2011.

BOUDREAU, J.W., RAMSTAD, P.M. Talentship, Talent Segmentation and Sustainability: A New HR Decision Science Paradigm for a New Strategy Definition. Human Resource Management, v.44, n.2,p. 129-136, 2005.

CARROL, A.B. A three-dimensional conceptual model of corporate performance. Academy of Management Review, p. 497-505, 1979.

CARROL, A.B.; SHABANA, K.M..The Business Case for Corporate Social Responsibility: A Review of Concepts, Research and Practice. International Journal of Management Reviews, v.12, n.1, p. 85-105, 2010.

CLARKSON, M. B. E. A stakeholder framework for analyzing and evaluating corporate social performance. Academy of Management Review, p. 92-117, 1995.

ELKINGTON, John. Towards the Sustainable Corporation: Win-Win-Win Business Strategies for Sustainable Development. California Management Review, 90-100, 1994.

ELKINGTON, J. Enter The Triple Bottom Line. In: HENRIQUES, A. e RICHARDSON, J. (Ed.). The Triple Bottom Line, Does it All Add Up? Assessing the Sustainability of Business and CSR. . London, UK: Earthscan, 2004. p.1-17.

Freeman, E. Strategic Management: A Stakeholder Approach, Pitman, Boston, MA, 1984.

FUENTES-GARCIA, F.J.; NUNEZ-TABALES, J.; VEROZ-HERRADO, R.; Applicability of Corporate Social Responsibility to Human Resources Management: Perspective from Spain. Journal of Business Ethics, v.82, p. 27-44, 2008.

FURTADO, R. A.; PENA, R.P.M. Responsabilidade Social Empresarial com o Público Interno: a Percepção dos Empregados da Promon. Revista de Gestão Social e Ambiental, v10, n.3, p.39-57, 2007.

GALBREATH, J. Building corporate social responsibility into strategy. European Business Review, v. 21, n. 2, p. 109-127, 2009.

Garriga, E.; MELÈ, D. Corporate social responsibility theories: mapping the territory. Journal of Business Ethics, v. 53, n. 1, p. 51-71, 2004.

Greenwood, M. Stakeholder Engagement: Beyond the Myth of Corporate Responsibility, Journal of Business Ethics, v.74, n.2 p. 315327, 2007.

GUIMARÃES, N.A. Quando a indústria se transforma... atores locais e políticas subnacionais de equidade de gênero e raça. São Paulo em Perspectiva, v. 18,n.4, p. 83-92, 2004.

HAIR, J. JR. et al. Fundamentos de Métodos de pesquisa em administração. Porto Alegre: Bookman, 2005.

INYANG, B.J.; AWA, H.O.A.; ENUOH, R.O. CSRHRM Nexus: Defining the Role Engagement of the Human Resources Professionals. International Journal of Business and Social Science, v. 2, n. 5, 2011.

JABBOUR, C.J.C.; SANTOS, F.C.A. The central role of human resource management in the search for sustainable organizations. The International Journal of Human Resource Management, v.19, n.12, p. 2133-2154, 2008.

JAMALI, D. A stakeholder approach to corporate social responsibility: a fresh perspective into theory and practice. Journal of Business Ethics, v. 82, n. 1, p. 213-231, 2008.

KIM, H.R.; LEE, M.; LEE, H.T.; KIM, N.M. 
Corporate Social Responsibility and Employee Company Identification. Journal of Business Ethics, v.95, p.557-569, 2010.

KORHONEN, J.; WIHERSAARI, M.; SAVOLAINEN, I. Industrial ecosystem in the Finnish forest industry: using the material and energy flow model of a forest ecosystem in a forest industry system. Ecological Economics, v. 39, n. 1, p. 145-161, 2001.

Lengnick-HALL, M.L.; Lengnick-HALL, C.A.; ANDRADE, L.S.;DRAKE, B. Strategic human resource management: The evolution of the field. Human Resource Management Review, v. 19, n. 1, p. 64-85, 2009.

Longo, M., MURA. M.; BONOLI, A. Corporate Social Responsibility and Corporate Performance: The Case of Italian SMEs'. Corporate Governance, v.5, n.4, p.28-42, 2005.

MAON, F.; SWAEN, V. Shaping the Processual View of CSR: A Multipartite SensemakingSensegiving Conceptualization. In: Procedings of Academy of Management Conference, August 7-11, Chicago, Illinois, U.S.A, 2009.

MATTEN, D; CRANE, A. Corporate citizenship: Toward an extended theoretical conceptualization. The Academy of Management Review, v. 30, n.1, p. 166-179, 2005.

MATTEN, D.; MOON, J. " Implicit" and" explicit" CSR: a conceptual framework for a comparative understanding of corporate social responsibility. The Academy of Management Review v. 33, n. 2, p. 404-424, 2008.

MCWILLIAMS, A.; SIEGEL, D. S.; WRIGHT, P. M. Corporate social responsibility: Strategic implications. Journal of Management Studies, v. 43, n. 1, p. 1-18, 2006.

MORAIS NETO, S.; PEREIRA, M. F. MACCARI, E. A. Classificando ações de sustentabilidade: uma análise de conteúdo de entrevistas de líderes. Revista de Administração da UFSM, v.
5, n. 1, p. 110-125, 2012.

Panapanaan, V.; Linnanen, L.; Karvonen, M.; Phan, V.Roadmapping corporate social responsibility in Finnish companies. Journal of Business Ethics, v. 44, n. 2/3, p. 133-48, 2003.

Papasolomou, D. I., KRAMBIA, K. M.; KATSIOULOUDES, M. Corporate Social Responsibility: The Way Forward? Maybe Not! European Business Review, v.17, n.3, p. 263279, 2005.

PEREIRA JR, A. O.; SOARES, J. B.; DE OLIVEIRA, R. G.; DE QUEIROZ, R. P. Energy in Brazil: Toward sustainable development? Energy Policy, v. 36, n. 1, p. 73-83, 2008.

PETRINI, M.; POZZEBON, M. Managing sustainability with the support of business intelligence: Integrating socio-environmental indicators and organisational context. Journal of Strategic Information Systems, v. 18, p. 178191, 2009.

PFEFFER, J. Building sustainable organizations: the human factor. The Academy of Management Perspectives, v. 24, n. 1, p. 3445, 2010.

Rodrigo, P.; ARENAS, D. Do Employees Care About CSR Programs? A Typology of Employees According to their Attitudes. Journal of Business Ethics, v.83, n.2, p. 265-283, 2008.

SACHS, I. Caminhos para o desenvolvimento sustentável. Rio de Janeiro: Garamond, 2002.

SASSE, C. M.; TRAHAN, R. T. Rethinking the new corporate philanthropy. Business Horizons, $v$. 50, n. 1, p. 29-38, 2007.

TACHIZAWA, T.; POZO, H. Gestão socioambiental e desenvolvimento sustentável: um indicador para avaliar a sustentabilidade empresarial. REDE - Revista Eletrônica do Prodeme, v. 1, n.1, p. 35-54, 2007.

TEIXEIRA, M. G. C; MORAES, I.B. O diálogo com os stakeholders na teoria e na prática: 
análise da relação de uma empresa publica do setor industrial com seus stakeholders para a construção de uma política de responsabilidade social. Rev. Adm. UFSM, Santa Maria, v. 6, Edição Especial, p. 211-228, 2013.

TURKER, D. Measuring Corporate Social Responsibility: A Scale Development Study. Journal of Business Ethics, v. 85, p. 411-427, 2009.

TOLFO, S.; PICCININI, V. C. As melhores empresas para trabalhar no Brasil e a qualidade de vida no trabalho: disjunções entre a teoria e a prática. Rev. adm. Contemp., Curitiba , v. 5, n. 1, 2011.

VAN MARREWIJK, M. Concepts and definitions of CSR and corporate sustainability: between agency and communion. Journal of Business Ethics, v. 44, n. 2, p. 95-105, 2003.

VENSON, A. B. S.; FIATES, G. G. S.; DUTRA, A.; CARNEIRO, M. L.; MARTINS, C. O recurso mais importante para as organizações são mesmo as pessoas? Uma análise da produção científica sobre qualidade de vida no trabalho (QVT) Rev. Adm. UFSM, Santa Maria, v. 6, n. 1, p. 139-156, 2013.

VERGARA, S.C.; BRANCO, P.D. Empresa Humanizada: a organização necessária e possível. Revista de Administração de Empresas, v.41, n.2, p. 20-30, 2001.

VITHESSONTHI, C. Corporate ecological sustainability strategy decisions: the role of attitude towards sustainable development. Journal of Organisation Transformation \& Social Change, v. 6, n. 1, p. 49-64, 2009.

WELFORD, R. Corporate Social Responsibility in Europe and Asia: Critical Elements and Best Practice, Journal of Corporate Citizenship, $v$. 13, n.1, p. 31-47, 2004.

WOOD, D. J. Corporate social performance revisited. Academy of Management Review, p. 691-718, 1991. 